\title{
COVID-19 and tuberculosis
}

\author{
Heng Yang, Shuihua Lu \\ Shanghai Public Health Clinical Center, Fudan University, Shanghai, China
}

\begin{abstract}
On March 11, 2020, the WHO declared that coronavirus disease 2019 (COVID-19) can be characterized as a pandemic based on the alarming levels of spread and severity and on the alarming levels of inaction. COVID-19 has received worldwide attention as emergency, endangering international public health and economic development. There is a growing body of literatures regarding severe acute respiratory syndrome coronavirus 2 (SARS-CoV-2) as well as COVID-19. This review will focus on the latest advance of epidemiology, pathogenesis, and clinical characteristics about COVID-19. Meanwhile, tuberculosis (TB) remains the leading representative respiratory tract communicable disease threatening public health. There are limited data on the risk of severe disease or outcomes in patients with concurrence of TB and COVID-19. Nevertheless, co-infection of some virus would aggravate TB, such as measles. And tuberculosis and influenza co-infection compared with tuberculosis single infection was associated with increased risk of death in individuals. This review will also introduce the characteristics about the concurrence of TB and emerging infectious diseases to provide a hint to manage current epidemic.
\end{abstract}

Key words: COVID-19, SARS-CoV-2, tuberculosis, clinical features, emerging infectious diseases, radiologic manifestation

\section{INTRODUCTION}

Coronavirus disease 2019 (COVID-19) is a communicable disease caused by severe acute respiratory syndrome coronavirus 2 (SARSCoV-2), a member of the Coronaviridae family, which also includes severe acute respiratory syndrome coronavirus (SARS$\mathrm{CoV}$ ) and Middle East respiratory syndrome coronavirus(MERS-CoV) $\cdot{ }^{[1]}$ It emerged in Huanan Seafood Wholesale Market in Wuhan, China, in December 2019 and continues to spread around the world. As of June 8, 2020, COVID-19 has been confirmed in 6,931,000 people worldwide. ${ }^{[2]}$ People are generally susceptible to SARSCoV-2, including children, but the highest burden is in middle-aged and old men. ${ }^{[3,4]}$ This outbreak is menacing and seriously threatens people's health and life with deaths, closures, and quarantines.

Under the pandemic situation, it is a key topic to do a good job in tuberculosis (TB) diagnosis and treatment management under the premise of how to ensure the safety of patients with TB. TB is the leading cause of death worldwide from an infectious disease among adults and has been considered a global public health emergency for the past 25 years. ${ }^{[5]}$ Globally, an estimated 10.0 million people fell ill with TB in 2018. There were an estimated 1.2 million TB deaths among HIVnegative people in 2018 and an additional 251,000 deaths among HIV-positive people..$^{[6]}$ During the epidemic period, clinicians still need to follow up, treat, and manage patients with TB, which is a major challenge for clinicians and patients with TB.

\section{SEVERE ACUTE RESPIRATORY SYNDROME CORONAVIRUS 2}
SARS-CoV-2, a new subtype of genus Betacoronavirus
Lu et al. ${ }^{[1]}$ performed next-generation sequencing of samples from bronchoalveolar lavage fluid and cultured isolates from nine 
inpatients and revealed the novel betacoronavirus. A Blastn search of the complete genomes of SARS-CoV-2 revealed that the most closely related viruses available on GenBank were bat-SL-CoVZC45 and another SARS-like betacoronavirus of bat origin, bat-SL-CoVZXC21. The SARS-CoV-2 were less genetically similar to SARS-CoV (about 79\%) and MERS-CoV (about 50\%). On the basis of phylogeny, taxonomy, and established practice, the Coronaviridae Study Group (CSG) of the International Committee on Taxonomy of Viruses formally recognizes this virus as a sister clade to SARS-CoVs of the species Severe acute respiratory syndrome-related coronavirus and designates it as SARS-CoV-2. ${ }^{[1,7]}$ Population genetic analyses of 103 SARS-CoV-2 genomes indicated that these viruses evolved into two major types (designated $\mathrm{L}$ and $\mathrm{S}$ ), with main differences in the proportion and possibly in virulence. ${ }^{[8]}$ However, MacLean et al. ${ }^{[9]}$ thought that two of the key claims made by this article seem to have been reached by misunderstanding and overinterpretation of the SARS-CoV-2 data, with an additional analysis suffering from methodological limitations.

\section{S-protein binds to ACE2 for virus entry into cell}

The coronavirus spike (S) glycoprotein is the structural protein responsible for the crown-like shape of the $\mathrm{CoV}$ viral particles from which the original name "coronavirus" was coined. The approximately 1200 aa long S-protein belongs to class-I viral fusion proteins and engages angiotensin-converting enzyme 2 (ACE2) as the entry receptor. ${ }^{[10-12]}$ SARS-CoV-2 have a receptor-binding domain (RBD) in the S-protein that binds with higher affinity to ACE2 from human than SARS-CoV presumably contributing to the phenylalanine $(\mathrm{F})$ at residue 486 in the $\mathrm{S}$ protein. ${ }^{[13-15]}$ Meanwhile, Walls et al. ${ }^{[16]}$ revealed that the SARS-CoV-2 recognizes human ACE2 with affinity comparable with that of SARS-CoV in the way of biolayer interferometry. Moreover, as the S-protein bind to ACE2 for entry, the S-protein is primed by TMPRSS2, a serine protease. A TMPRSS2 inhibitor was approved for clinical use blocked the entry and might constitute a treatment option. ${ }^{[12]}$ Using in silico structural modeling, Othman et al. ${ }^{[17]}$ showed the evidence that the interface segment of the spike protein RBD might be acquired by SARS-CoV-2 via a complex evolutionary process rather than mutation accumulation.

\section{Structural characterization of the S-protein in SARS-CoV-2, an implication for virus efficient transmission}

One notable feature of SARS-CoV-2 is the predicted furinlike recognition motif (RRAR) in the S-protein similar to that of MERS-CoV. Li et al. ${ }^{[18]}$ found that the SARS-CoV-2 virus sequence had redundant PRRA sequences. This furin-like motif site is supposed to be cleaved during virus egress for S-protein "priming." [11, 18-20] Li et al. proposed that the existence of such a motif may allow spikes to be cut into S1 and S2 by furin-like proteases before maturity, but not separated, which provides S1 with the flexibility to change the conformation to better fit the host receptor and easily fuse with host cell membrane. ${ }^{[18]}$ The experiments with SARS-CoV have shown that engineering such a site enhances cell-cell fusion but does not affect virus entry. ${ }^{[21]}$ It may provide a gain of function to the SARSCoV-2 for efficient spreading in the human population compared with other lineage betacoronaviruses.

\section{IMMUNOLOGICAL FEATURES AND PATHOLOGICAL CHANGES IN PATIENTS SEVERELY INFECTED WITH SARS-COV-2}

Accumulating evidence indicates that a subgroup of patients with severe COVID-19 might have a cytokine storm syndrome or an increase in inflammatory cytokines. ${ }^{\left[22,{ }^{23]}\right.}$ Zhou et al. ${ }^{[24]}$ showed that after the SARSCoV-2 infection, CD4+ T lymphocytes are rapidly activated to become pathogenic $\mathrm{T}$ helper (Th) 1 cells and generate granulocyte-macrophage colony-stimulating factor (GM$\mathrm{CSF})$. The cytokine environment induces inflammatory CD14+CD16+ monocytes with high expression of IL-6 and accelerates the inflammation. Wang et al. ${ }^{[25]}$ discovered that there were an overactivation of T cells, manifested by the increase in Th17 and high cytotoxicity of CD8+ T cells in the peripheral blood of a patient with severe COVID-19. After this patient died because of this disease, they investigated the pathological characteristics of postmortem biopsies. The lung' histological examination showed bilateral diffuse alveolar damage with cellular fibromyxoid exudates. The right lung shows evident desquamation of pneumocytes and hyaline membrane formation, indicating acute respiratory distress syndrome (ARDS). Left lung tissue displayed pulmonary edema with hyaline membrane formation, suggestive of early-phase ARDS and interstitial mononuclear inflammatory infiltrates. Cytokine storm syndrome can account for the lung injury in patients with severe COVID-19.

\section{CLINICAL CHARACTERISTICS OF COVID-19}

\section{Demographic and clinical features}

As of June 08, 2020, COVID-19 has been confirmed in 6,931,000 people worldwide, carrying a mortality of approximately $5.78 \% .^{[2]}$ The Chinese Center for Disease Control and Prevention classified 44,415 patients with COVID-19 into diseases with light type (no pneumonia or 
mild pneumonia) accounting for 81\% (36,160 cases) and critical type accounting for 5\% (2087 cases). The overall case fatality rate (CFR) was 2.3\% (1023 death among 44,672 confirmed cases). The crude death rate was $2.9 \%$ in Hubei province and $0.4 \%$ in other provinces. Patients older than 80 years got the highest CFR, with a crude CFR of $14.8 \%{ }^{\left[{ }^{[4]}\right.}$

Guan et al. ${ }^{[26]}$ studied 1099 patients with COVID-19 in China and found that the median incubation period was 3.0 days (range, $0-24.0$ days). The common symptoms during the onset were fever $(87.9 \%)$, cough $(67.7 \%)$, fatigue $(38.1 \%)$, expectoration (33.4\%), shortness of breath $(18.6 \%)$, muscle pain or joint pain $(14.8 \%)$, and other non-specific symptoms, including nasal congestion, chills, headache, pharyngalgia, nausea, vomiting, and diarrhea.

\section{Differences in disease severity between Wuhan and other provinces in china}

Huang et al. ${ }^{[27]}$ described the epidemiological and clinical characteristics of 99 cases of patients with COVID-19 in Wuhan, China, and among them, 11 (11\%) patients worsened in a short period of time and died of multiple organ failure. However, Xu et al. ${ }^{[28]}$ compared 62 patients outside of Wuhan, China, and found that the symptoms of the patients were relatively mild. And trace back to the data released by the local health Committee, the death toll was 0 (Table 1). Meanwhile, Cheng et al. ${ }^{[29]}$ reported that there were 72 severe cases $(5.7 \%)$ in 1265 patients with COVID-19, and the fatality rate was $1.5 \%$ in Henan province. All these indicate that Hubei Province, the initial city with outbreak of COVID-19, which constitutes the majority of the patients with COVID-19, has a higher disease severity. A retrospective, multicenter cohort study included 191 patients in Wuhan, of whom 137 were discharged and 54 died in hospital. Multivariable regression showed increasing odds of inhospital death associated with older age, higher Sequential Organ Failure Assessment (SOFA), and d-dimer greater than $1 \mu \mathrm{g} / \mathrm{mL}$ on admission. ${ }^{[30]}$

\section{THERAPY FOR COVID-19}

At the moment, the WHO recommended early supportive therapy and management of hypoxemic respiratory failure and acute respiratory distress syndrome (ARDS) and septic shock without specific therapeutic drugs. ${ }^{[32]}$ Wang et al. ${ }^{[33]}$ found that remdesivir and chloroquine are highly effective in the control of SARS-CoV-2 infection in vitro. Treatment with remdesivir was found to be effective against a patient with COVID-19 when he was on a worsening clinical status. ${ }^{[34]}$ However, Rosenberg et al. ${ }^{[35]}$ discovered that treatment with hydroxychloroquine was not significantly associated with differences in inhospital mortality. Mehta et al. ${ }^{[22]}$ recommended that all patients with severe COVID-19 need to consider immunosuppressive therapeutic options, including steroids, intravenous immunoglobulin, and selective cytokine blockade. Shang et al. ${ }^{[36]}$ recommended short courses of corticosteroids at low-to-moderate dose,

\begin{tabular}{|c|c|c|}
\hline \multirow[t]{2}{*}{ Clinical and epidemiologic aspects } & Wuhan & Zhejiang \\
\hline & $n=99(\%)$ & $n=62(\%)$ \\
\hline Male & $67(68 \%)$ & $35(56 \%)$ \\
\hline \multicolumn{3}{|l|}{ Coexisting conditions } \\
\hline Any & $50(51 \%)$ & $20(32 \%)$ \\
\hline Cardiovascular and cerebrovascular diseases & $40(40 \%)$ & $6(10 \%)$ \\
\hline Digestive system disease & $11(11 \%)$ & $7(11)$ \\
\hline Endocrine system disease & $13(13 \%)$ & $1(2 \%)$ \\
\hline Respiratory system disease & $1(1 \%)$ & $1(2 \%)$ \\
\hline \multicolumn{3}{|l|}{ Signs and symptoms at admission } \\
\hline Fever & $82(83 \%)$ & $48(77 \%)$ \\
\hline Cough & $81(82 \%)$ & $50(81 \%)$ \\
\hline Shortness of breath & $31(31 \%)$ & $2(3 \%)$ \\
\hline Myalgia or fatigue & $11(11 \%)$ & $32(52 \%)$ \\
\hline Headache & $8(8 \%)$ & $21(34 \%)$ \\
\hline Sore throat & $5(5 \%)$ & $\begin{array}{l}\text { Not } \\
\text { mentioned }\end{array}$ \\
\hline Rhinorrhea & $4(4 \%)$ & Not mentioned \\
\hline Diarrhea & Not mentioned & $3(8 \%)$ \\
\hline More than one sign or symptom & 89 (90\%) & Not mentioned \\
\hline \multicolumn{3}{|l|}{ Treatment and outcome } \\
\hline Mechanical ventilation & $17(17 \%)$ & $1(2 \%)$ \\
\hline Death & $11(11 \%)$ & 0 \\
\hline
\end{tabular}


used prudently, for critically ill patient with COVID-19.

\section{TUBERCULOSIS AND EMERGING INFECTIOUS DISEASES COINFECTION}

\section{A further realization on tuberculosis}

TB is a major infectious respiratory disease that continues to cause noticeable morbidity and mortality globally. The $\mathrm{WHO}^{[6]}$ reported 10 million new cases of $\mathrm{TB}$ worldwide in 2018 , of which $85 \%$ were newly sick from TB, with 500,000 new rifampin-resistant TB cases. It is estimated that about 1.7 billion people worldwide are infected with $\mathrm{TB},{ }^{[37]}$ but only $5-15 \%$ will develop active TB. ${ }^{[38]}$ Drain et al. ${ }^{[39]}$ proposed that the complex bacterial and host dynamics resulted in the pathology of TB disease falling on a spectrum of TB status of no infection, latent through incipient and subclinical disease, to overt active disease. The host immune response is clearly needed to prevent Mycobacterium tuberculosis infection and control disease. However, Tezera et al. ${ }^{[40]}$ thought merely driving a stronger immune response may not improve the control of the pathogen referring to the development of active TB associated with cancer treatment by immune checkpoint inhibition and gave a new view on reconsidering the optimal immune response to $M$. tuberculosis.

The typical clinical manifestations of pulmonary TB include cough lasting for longer than 2 weeks, hemoptysis, weight loss, fever, and night sweats. ${ }^{[4]} \mathrm{TB}$ is diagnosed as bacteriologically confirmed and clinically diagnosed TB case; a bacteriologically confirmed TB case is one from whom a biological specimen is positive by smear microscopy, culture, or the WHO-approved rapid diagnostics (such as Xpert MTB/RIF). A clinically diagnosed TB case is one who does not fulfill the criteria for bacteriological confirmation but has been diagnosed with active TB by a clinician or other medical practitioner who has decided to give the patient a full course of treatment for TB. This definition includes cases diagnosed based on X-ray abnormalities or suggestive histology and extrapulmonary cases without laboratory confirmation. ${ }^{[4]}$ Diagnostic methods of TB include clinical manifestations, radiological evidence, and various bacteriological evidence showing the existence of $M$. tuberculosis. For many years, WHO has recommended chest radiography as a diagnostic tool to be used as a complementary part of the clinical diagnosis of bacteriologically negative TB. Recently, chest radiography has been promoted as a useful tool that can be placed early in screening and triaging algorithms ${ }^{[43]}$ CT scan has higher density resolution and specificity, can find many patients who missed and misdiagnosed by X-ray chest plain film, and can make an early diagnosis of pulmonary
TB, especially for patients without any bacteriological evidence. ${ }^{[4]}$ In 2020, the $\mathrm{WHO}^{[45]}$ recommended molecular assays as initial tests for the diagnosis of TB and rifampicin resistance instead of sputum smear microscopy. Molecular assays contain Xpert MTB/RIF and Xpert Ultra and can improve the prognosis of patients. ${ }^{[44]}$ Drug-susceptible patients should be treated with first-line anti-TB drugs. ${ }^{[46]}$ For drug-resistant TB, the WHO recently recommended that a shorter therapeutic regimen of 9-12 months may be used instead of the longer regimens. ${ }^{[47]}$

\section{Pulmonary tuberculosis and respiratory virus infectious diseases}

TB and respiratory viral infectious diseases, including COVID-19, have certain similarities. They are mainly to invade susceptible populations through droplet transmission or other transmission routes from infectious sources. Patients with TB also suffer from acute respiratory infectious diseases. During the SARS epidemic in 2003, Liu et al. ${ }^{[48]}$ reported 3 patients with SARS with chest radiographs consistent with active disease were identified as having pulmonary TB among 83 patients with SARS. Patient 1 was also diagnosed with bacteriologically confirmed TB when he was diagnosed with SARS. Patients 2 and 3 were known to have cases of pulmonary TB and became infected with SARS-CoV after contact with other patients hospitalized for SARS. In Singapore, of 236 patients with probable SARS, 2 were co-infected with TB. One of them suddenly developed a dry cough and was later diagnosed as pulmonary TB after nearly full recovery from SARS. The other case was traced back to sputum culture and found M. tuberculosis in sputum. The author thought it is possible that infection with the SARS-CoV causes a temporary suppression of cellular immunity, which further predisposed the two patients to aggravate reactivation or new infection with TB. ${ }^{[49]}$

The impact of concurrent TB and influenza is not conclusive, but most researchers think that when concurrent infection occurs, the disease is more likely to worsen. Mendy et al..$^{[50]}$ found that among 282 patients with active TB, 12 were co-infected with FluA or FluB. The TB/Flu co-infected patients had a significantly higher bacterial load compared with those with TB monoinfection. Walaza et al. ${ }^{[1]}$ observed an increased risk of influenza-associated mortality in persons with PTB compared with non-TB respiratory death based on the analysis of information in South Africa, 1999-2009. Walaza et al. ${ }^{[52]}$ described the characteristics of patients with laboratory-confirmed TB, laboratory-confirmed influenza, and TB-influenza co-infection in South Africa, 2010-2011.They found TB and influenza co-infection compared to TB monoinfection was associated with increased risk of death in individuals with symptoms $\geq 7$ 
days. Abadom et al. ${ }^{[53]}$ reported that TB was a risk factor for influenza-associated hospitalization. However, data on the incidence of TB in Korea before and after influenza $\mathrm{A}(\mathrm{H} 1 \mathrm{~N} 1)$ virus infection and 7 cases of concurrent active pulmonary TB and H1N1 virus infection in South Korea, Noh et al. ${ }^{[54]}$ assumed that the concurrence of TB and influenza could be a simple overlap.

\section{The difference of imaging between tuberculosis and COVID-19}

Ground-glass opacities (GGO) are the most common patterns on chest computed tomography (CT) in patients with COVID-19. ${ }^{[33,55]}$ Guan et al. ${ }^{[26]}$ described that chest radiographs were abnormal in 840 of 1099 (76.4\%) patients. Of these 840 patients, 550 had GGO and 505 had bilateral patchy shadowing. Other common abnormalities include local patchy shadowing and interstitial abnormalities. Considerably more severe cases were diagnosed by symptoms plus reverse-transcriptase polymerase-chain-reaction without abnormal radiological findings than non-severe cases. Pan et al. ${ }^{[5]}$ studied lung changes on chest CT during recovery from 21 patients. Initial lung findings on chest CT were small subpleural GGO that grew larger with crazy-paving pattern and consolidation in the following 2 weeks. Eventually, the lesion was absorbed, leaving extensive GGO and subpleural parenchyma bands.

Primary TB manifests with three main entities: parenchymal disease, lymphadenopathy, and pleural effusion. At CT studies, the appearance of the parenchymal consolidations in primary TB is most commonly dense and homogeneous ${ }^{[56,57]}$ In most cases of reactivation TB, more than one pulmonary segment is involved, with bilateral disease seen in one-third to two-thirds of cases. On CT scans, bronchogenic spread can be identified in $95 \%$ of patients with post-primary TB. ${ }^{[58]}$ "Tree-in-bud" appearances were advised to judge whether the disease is active or not. ${ }^{[58,59]}$ About $50 \%$ of patients are affected by the cavitation, the hallmark of postprimary TB. ${ }^{[0]}$

\section{CONCLUSIONS}

Since the influence of SARS-CoV-2 and possible immunosuppressive drugs, the immunological function can be temporarily inhibited, resulting in active TB caused by reactivation or infection of $M$. tuberculosis. Moreover, it is likely to exacerbate the course of the disease for the co-infected population. We should be sensitive to the shortterm increase in TB epidemic after the end of the pandemic of COVID-19. This requires not only practicing prevention and control of TB but also adequate measures to strengthen the prevention, control, and management of TB.

\section{Conflict of Interest}

The authors have no conflicts of interest to disclose.

\section{REFERENCES}

1. Lu R, Zhao X, Li J, Niu P, Yang B, Wu H, et al. Genomic characterisation and epidemiology of 2019 novel coronavirus: implications for virus origins and receptor binding. Lancet 2020; 395: 565-74.

2. WHO [Internet]. Coronavirus disease 2019 (COVID-19) situation report - 140. June 08, 20,2020. [cited 2020 June 09]. [about 17 screens]. Available from: https://ww.who.int/docs/default-source/coronaviruse/situationreports/20200608-covid-19-sitrep-140.pdf?sfvrsn=2f310900_2. Accessed on June 08, 2020.

3. Liu W, Zhang Q, Chen J, Xiang R, Song H, Shu S, et al. Detection of Covid-19 in Children in Early January 2020 in Wuhan, China. New Engl J Med 2020; April 2.

4. Wu Z, McGoogan JM. Characteristics of and Important Lessons From the Coronavirus Disease 2019 (COVID-19) Outbreak in China: Summary of a Report of 72314 Cases From the Chinese Center for Disease Control and Prevention. JAMA 2020; Feb 24.

5. Nathavitharana RR, Friedland JS. A tale of two global emergencies: tuberculosis control efforts can learn from the Ebola outbreak. Eur Respir J 2015; 46: 293-6.

6. World Health Organization. Global tuberculosis report 2019. Geneva: World Health Organization; 2019. Available from: https://www.who.int/ tb/publications/global_report/en/. Access May 19, 2020.

7. Gorbalenya AE, Baker SC, Baric RS, de Groot RJ, Drosten C, Gulyaeva $\mathrm{AA}$, et al. The species Severe acute respiratory syndrome-related coronavirus: classifying 2019-nCoV and naming it SARS-CoV-2. Nat Microbiol 2020; 5: 536-44.

8. Tang X, Wu C, Li X, Song Y, Yao X, Wu X, et al. On the origin and continuing evolution of SARS-CoV-2. Natl Sci Rev 2020; Mar 20.

9. Virological [Internet]. Response to "On the origin and continuing evolution of SARS-CoV-2" [cited 2020 Mar 7]. [about 7 screens]. Available from: http://virological.org/t/response-to-on-the-origin-and-continuing-evolution-of-sars-cov-2/418. Access May 19, 2020.

10. Lu G, Wang Q, Gao GF. Bat-to-human: spike features determining 'host jump' of coronaviruses SARS-CoV, MERS-CoV, and beyond. Trends Microbiol 2015; 23: 468-78.

11. Millet JK, Whittaker GR. Host cell entry of Middle East respiratory syndrome coronavirus after two-step, furin-mediated activation of the spike protein. Proc Nat Acad Sc U S A 2014; 111: 15214-9.

12. Hoffmann M, Kleine-Weber H, Schroeder S, Krüger N, Herrler T, Erichsen S, et al. SARS-CoV-2 Cell Entry Depends on ACE2 and TMPRSS2 and Is Blocked by a Clinically Proven Protease Inhibitor. Cell 2020; 181 : 271-280.e8.

13. Sheahan T, Rockx B, Donaldson E, Sims A, Pickles R, Corti D, et al. Mechanisms of Zoonotic Severe Acute Respiratory Syndrome Coronavirus Host Range Expansion in Human Airway Epithelium. J Virol 2008; 82: 2274-85.

14. Wan Y, Shang J, Graham R, Baric RS, Li F. Receptor recognition by novel coronavirus from Wuhan: An analysis based on decade-long structural studies of SARS. J Virol 2020; 94(7). pii: e00127-20.

15. Wrapp D, Wang N, Corbett KS, Goldsmith JA, Hsieh C, Abiona O, et al. Cryo-EM Structure of the 2019-nCoV Spike in the Prefusion Conformation. Science 2020; 367: 1260-3.

16. Walls AC, Park Y, Tortorici MA, Wall A, McGuire AT, Veesler D. Structure, Function, and Antigenicity of the SARS-CoV-2 Spike Glycoprotein. Cell 2020; 181: 281-292.e6.

17. Othman H, Bouslama Z, Brandenburg JT, da Rocha J, Hamdi Y, Ghedira $\mathrm{K}$, et al. . In silico study of the spike protein from SARS-CoV-2 interaction with ACE2: similarity with SARS-CoV, hot-spot analysis and effect 
of the receptor polymorphism. 2020; Mar 7.

18. Li H, Wu CR, Yang YY, Chen L, Zheng M, Yang L, et al. Furin, a potential therapeutic target for COVID-19. Available from: http://www.chinaxiv. org/home.htm. Access May 19, 2020.

19. Zhang T, Wu Q, Zhang Z. Probable pangolin origin of SARS-CoV-2 associated with the COVID-19 outbreak. Curr Biol 2020; 30: 1346-51.

20. Coutard B, Valle C, de Lamballerie X, Canard B, Seidah NG, Decroly E. The spike glycoprotein of the new coronavirus 2019-nCoV contains a furin-like cleavage site absent in $\mathrm{CoV}$ of the same clade. Antivir Res 2020; 176: 104742 .

21. Follis KE, York J, Nunberg JH. Furin cleavage of the SARS coronavirus spike glycoprotein enhances cell-cell fusion but does not affect virion entry. Virology 2006; 350: 358-69.

22. Mehta P, McAuley DF, Brown M, Sanchez E, Tattersall RS, Manson JJ; HLH Across Speciality Collaboration, UK. COVID-19: consider cytokine storm syndromes and immunosuppression. Lancet 2020; 395: 1033-4.

23. Wang Z, Yang B, Li Q, Wen L, Zhang R. Clinical Features of 69 Cases with Coronavirus Disease 2019 in Wuhan, China. Clin Infect Dis 2020; Mar 16.

24. Zhou Y, Fu B, Zheng X, Wang D, Zhao C, Qi Y, et al. Pathogenic T cells and inflammatory monocytes incite inflammatory storm in severe COVID-19 patients. Natl Sci Rev 2020; Mar 13.

25. Wang FS, Xu Z, Shi L, Wang Y, Zhang J, Huang L, Zhang C, et al. Pathological findings of COVID-19 associated with acute respiratory distress syndrome. Lancet Respir Med 2020; 8: 420-2.

26. Guan W, Ni Z, Hu Y, Liang W, Ou C, He J, et al. Clinical Characteristics of Coronavirus Disease 2019 in China. New Engl J Med 2020; 382: 1708-20.

27. Huang C, Wang Y, Li X, Ren L, Zhao J, Hu Y, et al. Clinical features of patients infected with 2019 novel coronavirus in Wuhan, China. Lancet 2020; 395: 497-506.

28. Xu XW, Wu XX, Jiang XG, Xu KJ, Ying LJ, Ma CL, , et al. Clinical findings in a group of patients infected with the 2019 novel coronavirus (SARSCov-2) outside of Wuhan, China: retrospective case series. BMJ 2020; $368: \mathrm{m} 606$.

29. Cheng JL, Huang C, Zhang GJ, Liu DW, Li P, Lu CY, et al. Epidemiological characteristics of novel coronavirus pneumonia in Henan. Zhonghua Jiehe He Huxi Zazhi 2020; 43: E27.

30. Zhou F, Yu T, Du R, Fan G, Liu Y, Liu Z, et al. Clinical course and risk factors for mortality of adult inpatients with COVID-19 in Wuhan, China: a retrospective cohort study. Lancet 2020; Mar 11.

31. Clinical findings in a group of patients infected with the 2019 novel coronavirus (SARS-Cov-2) outside of Wuhan, China: retrospective case series. BMJ 2020; 368:m792.

32. WHO. Clinical management of severe acute respiratory infection when novel coronavirus (2019-nCoV) infection is suspected. Available from: https://www.who.int/publications-detail/clinical-management-ofsevere-acute-respiratory-infection-when-novel-coronavirus-(ncov)infection-is-suspected. Access May 19, 2020.

33. Wang M, Cao R, Zhang L, Yang X, Liu J, Xu M, et al. Remdesivir and chloroquine effectively inhibit the recently emerged novel coronavirus (2019-nCoV) in vitro. Cell Res 2020; 30: 269-71.

34. Holshue ML, DeBolt C, Lindquist S, Lofy KH, Wiesman J, Bruce H, et al. First Case of 2019 Novel Coronavirus in the United States. New Engl J Med 2020; 382: 929-36.

35. Rosenberg ES, Dufort EM, Udo T, Wilberschied LA, Kumar J, Tesoriero J, et al. Association of Treatment With Hydroxychloroquine or Azithromycin With In-Hospital Mortality in Patients With COVID-19 in New York State. JAMA 2020; E1-10

36. Shang L, Zhao J, Hu Y, Du R, Cao B. On the use of corticosteroids for 2019-nCoV pneumonia. Lancet 2020; 395: 683-4.

37. Global, regional, and national incidence, prevalence, and years lived with disability for 354 diseases and injuries for 195 countries and territories, 1990-2017: a systematic analysis for the Global Burden of Disease Study 2017. Lancet 2018; 392: 1789-858.
38. Houben RMGJ, Dodd PJ. The Global Burden of Latent Tuberculosis Infection: A Re-estimation Using Mathematical Modelling. Plos Med 2016; 13: e1002152.

39. Drain PK, Bajema KL, Dowdy D, Dheda K, Naidoo K, Schumacher SG, et al. Incipient and Subclinical Tuberculosis: a Clinical Review of Early Stages and Progression of Infection. Clin Microbiol Rev 2018; 31: e18e21.

40. Tezera LB, Mansour S, Elkington P. Reconsidering the Optimal Immune Response to Mycobacterium tuberculosis. Am J Resp Crit Care 2020; 201: 407-13.

41. World Health Organization. Systematic screening for active tuberculosis: an operational guide. Geneva: World Health Organization, 2015. Available from: https://www.who.int/tb/publications/systematic_screening/ en/. Access on May 19, 2020.

42. World Health Organization. Definitions and reporting framework for tuberculosis - 2013 revision: updated December 2014 and January 2020. Geneva: World Health Organization, 2013. Available from: https://www. who.int/tb/publications/definitions/en/. Access on May 19, 2020.

43. World Health Organization. Chest radiography in tuberculosis detection: summary of current WHO recommendations and guidance on programmatic approaches. Geneva: World Health Organization, 2016. Available from: https://www.who.int/tb/publications/chest-radiography/ en/. Accessed on May 19, 2020.

44. Ko JM, Park HJ, Kim CH. Pulmonary changes of pleural TB: up-to-date CT imaging. Chest 2014; 146: 1604-11.

45. World Health Organization. Molecular assays intended as initial tests for the diagnosis of pulmonary and extrapulmonary $\mathrm{TB}$ and rifampicin resistance in adults and children: rapid communication. Geneva: World Health Organization, 2020. Available from: https://www.who.int/publications-detail/rapid-communication-molecular-assays-as-initial-testsfor-the-diagnosis-of-tuberculosis-and-rifampicin-resistance. Accessed on May 19, 2020.

46. World Health Organization. Treatment of tuberculosis: guidelines. Geneva: World Health Organization, 2010. Available from: https://www. who.int/tb/publications/2010/9789241547833/en/. Accessed on May 19, 2020.

47. World Health Organization. WHO consolidated guidelines on drugresistant tuberculosis treatment. Geneva: World Health Organization, 2019. Available from: https://www.who.int/tb/publications/2019/ consolidated-guidelines-drug-resistant-TB-treatment/en/. Accessed on May 19, 2020.

48. Liu W, Fontanet A, Zhang P, Zhan L, Xin Z, Tang F, et al. Pulmonary tuberculosis and SARS, China. Emerg Infect Dis 2006; 12:707-9.

49. Low JG, Lee CC, Leo YS, Low JG, Lee CC, Leo YS.. Severe Acute Respiratory Syndrome and Pulmonary Tuberculosis. Clin Infect Dis 2004; 38 : e123-5.

50. Mendy J, Jarju S, Heslop R, Bojang AL, Kampmann B, Sutherland JS. Changes in Mycobacterium tuberculosis-Specific Immunity With Influenza co-infection at Time of TB Diagnosis. Front Immunol 2019; 9: 3093.

51. Walaza S, Cohen C, Nanoo A, Cohen AL, McAnerney J, von Mollendorf $\mathrm{C}$, et al. Excess Mortality Associated with Influenza among Tuberculosis Deaths in South Africa, 1999-2009. Plos One 2015; 10: e129173.

52. Walaza S, Tempia S, Dawood H, Variava E, Moyes J, Cohen AL, et al. Influenza virus infection is associated with increased risk of death amongst patients hospitalized with confirmed pulmonary tuberculosis in South Africa, 2010-2011. BMC Infect Dis 2015; 15: 26.

53. Abadom TR, Smith AD, Tempia S, Madhi SA, Cohen C, Cohen AL. Risk factors associated with hospitalisation for influenza-associated severe acute respiratory illness in South Africa: A case-population study. Vaccine 2016; 34: 5649-55.

54. Noh JY, Lee J, Choi WS, Song JY, Seo YB, Kim IS, et al. Concurrent tuberculosis and influenza, South Korea. Emerg Infect Dis 2013; 19: 165-7.

55. Pan F, Ye T, Sun P, Gui S, Liang B, Li L, et al. Time Course of Lung 
Changes on Chest CT During Recovery From 2019 Novel Coronavirus (COVID-19) Pneumonia. Radiology 2020; Feb 13.

56. McAdams HP, Erasmus J, Winter JA. Radiologic manifestations of pulmonary tuberculosis. Radiol Clin North Am 1995; 33: 655-78.

57. Cardinale L, Parlatano D, Boccuzzi F, Onoscuri M, Volpicelli G, Veltri A. The imaging spectrum of pulmonary tuberculosis. Acta Radiol 2015; 56: 557-64.

58. Hatipoğlu ON, Osma E, Manisali M, Uçan ES, Balci P, Akkoçlu A, et al. High resolution computed tomographic findings in pulmonary tuberculosis. Thorax 1996; 51: 397-402.
59. Nam KJ, Jeong YJ, Kim YD, Kim KL, Lee JW, Park HK, et al. Chronic destructive pulmonary tuberculosis: assessment of disease activity by computed tomography. Acta Radiologica2012, 53:1014-1019.

60. Burrill J, Williams CJ, Bain G, Conder G, Hine AL, Misra RR. Tuberculosis: A Radiologic Review. RadioGraphics 2007; 27: 1255-73.

How to cite this article: Yang H, Lu S. COVID-19 and tuberculosis. J Transl Intern Med 2020; 8: 59-65. 